\title{
Running head: WHEN THE CHIPS ARE DOWN
}

When the chips are down: Effects of attributional feedback on self-efficacy and task performance following initial and repeated failure

Submitted: $14^{\text {th }}$ May 2010

Resubmitted: $24^{\text {th }}$ August 2010 


\title{
WHEN THE CHIPS ARE DOWN 2
}

\begin{abstract}
In two experiments, we manipulated the controllability and stability of causes of failure and explored the impact of these factors on self-efficacy and performance. In Experiment 1, participants $(N=80$; mean age $20.03, S D 1.03$ years) were provided with false negative feedback following performance on a blindfolded dart throwing task. Consistent with theory and recent research, an induced belief that failure was beyond control and unlikely to change led to lower self-efficacy and worse performance, $F_{\mathrm{s}}(1,75)>5.49, p \mathrm{~s}<.05, \eta^{2} \mathrm{~s}=.01$. A second experiment $(N=80$; mean age 21.96, SD 2.10 years) demonstrated that following an induced belief that failure was beyond control and unlikely to change, only new perceptions that a repeated failure was within one's control and likely to change resulted in higher self-efficacy and improved performance, $F \mathrm{~s}(1,75)>4.53, p \mathrm{~s}<.05, \eta^{2} \mathrm{~s}>.004$. All effects were mediated by self-efficacy, Sobel's (1982) test, $z \mathrm{~s}>1.97$ (in absolute magnitude), $p \mathrm{~s}<.05, r \mathrm{~s}>.22$ (in absolute magnitude). These findings suggest that in novel circumstances individuals believe in the best for themselves unless possibilities to self-enhance are explicitly precluded and only reinvest efforts when opportunities for self-enhancement become clearly admissible.
\end{abstract}

Key words: controllability, stability, mediation, moderation 


\section{WHEN THE CHIPS ARE DOWN 3}

Introduction

Attributions are explanations about why particular behaviours have occurred, and explanations enhance people's ability to predict and control events in the future (Anderson \& Riger, 1991). A large body of psychological theory suggests that causal attributions following failure can play a significant role in shaping people's sense of self-efficacy and their subsequent performance (Abramson, Seligman, \& Teasdale, 1978; Bandura, 1997; Weiner, 1985). However, empirical evidence that links such attributions to subsequent performance is sparse. Instead, links are generally made between attributions and indices of behaviour, such as expectations for future success (e.g., Orbach, Singer, \& Price, 1999; for a review see, Weiner, 1986), efficacy (e.g., Allen, Jones, \& Sheffield, 2009; Bandura, 1997; Bond, Biddle, \& Ntoumanis, 2001; Coffee \& Rees, 2008, 2009; Gernigon \& Delloye, 2003), persistence (e.g., Le Foll, Rascle, \& Higgins, 2006, 2008; Rascle, Le Foll, \& Higgins, 2008), learned helplessness (e.g., Alloy, Peterson, Abramson, \& Seligman, 1984), and depression (e.g., Anderson, 1999). To address this gap in the literature, the present article reports the results of two experiments that examine the interactive effects of attributions for failure on self-efficacy and objective task performance.

In the present experiments, we focus on two key dimensions of attributions: controllability and stability. Controllability refers to the degree to which the causes of outcomes are seen to be under one's direct control; stability refers to a belief that the causes of outcomes are unlikely to change. Few researchers have examined the effects of attributions for failure upon subsequent performance; and these have produced inconsistent findings. For example, Rudisill (1988) and Orbach et al. (1999) reported no effects for attribution manipulations upon subsequent performance. On the other hand, Rudisill (1989) and Orbach, Singer, and Murphey (1997) found that performance was enhanced for participants who were orientated toward 


\section{WHEN THE CHIPS ARE DOWN 4}

attributions that were controllable and unstable. Recently, drawing upon research on selfenhancement (e.g., Kurman, 2006; Sedikides, Gaertner, \& Toguchi, 2003) and attributions (e.g., Abramson et al., 1978; Collins, 1996), Coffee, Rees, and Haslam (2009) reported results demonstrating that, following failure, attributions to uncontrollable and stable causes produced significantly lower levels of self-efficacy and performance in contrast to conditions where attributions were made to causes that were controllable and/or unstable. Similarly, in the attributional style literature, Seligman, Nolen-Hoeksema, Thornton, and Thornton (1990) demonstrated that only swimmers with a negative attributional style (which involves, among other factors, explaining bad events by causes that are stable across time) experienced a significant decline in performance following simulated failure.

Theorists (e.g., Bandura, 1986, 1997; Gist \& Mitchell, 1992) have suggested that attributions influence future behaviour, such as performance, through the mediation of, for example, self-efficacy. A number of researchers in sport have examined main effects of attributions upon self-efficacy.In a study with 81 golfers, Bond et al. (2001) found that following perceived success, self-efficacy was enhanced when attributions were made to stable causes. With 62 national level sprinters, Gernigon and Delloye (2003) reported that self-efficacy was enhanced when unexpected results were attributed to either controllable or unstable factors, dependent upon varying conditions. Anderson and Riger (1991) noted that interactive effects of attributions may well be important. For example, having failed at a task, a performer might comment, "I was unlucky" (an uncontrollable attribution), together with "and this is something that always affects my performance" (a stable attribution). Another might say, "I failed because my strategy was poor" (a controllable attribution), "but this is something that can change" (an unstable attribution). Carver (1989) argued that the most appropriate strategy for examining the 


\section{WHEN THE CHIPS ARE DOWN 5}

style of thinking outlined in the preceding examples would be to test for interactive effects of attribution dimensions. In response to these calls, moving beyond examining main effects of attributions alone, Coffee and Rees $(2008,2009)$ reported interactive effects for controllability and stability attributions upon self-efficacy. Coffee and Rees demonstrated that if the causes of less successful performances are perceived as relatively stable, higher levels of controllability are associated with higher levels of self-efficacy.

Although it has been suggested (e.g., Bandura, 1986, 1997; Gist \& Mitchell, 1992) that self-efficacy may mediate the effects of attributions upon behaviour, such as performance, relatively few researchers have examined such proposals. Those that have examined this issue have typically reported mediation of main effects or additive effects of attribution dimensions upon outcomes. For example, with reference to controllability, Litt (1988) using a cold-pressor task demonstrated that self-efficacy expectations mediated the desirability of providing control, and Haney and Long (1995) using a shooting task reported that self-efficacy mediated the control-performance relationship. Focussing on additive effects of attributions, Shields, Brawley, and Lindover (2006) across a 12-week exercise programme reported that self-efficacy mediated additive effects of attributions upon behaviour. As we have noted, however, interactive effects of attribution dimensions may well be important, coupled with examining the mechanisms through which interactions affect subsequent behaviour/performance.

In the present article we contribute to the literature in three ways: First, we replicate and extend novel findings. Second, we move beyond examining main effects of attributions to exploring interactive effects (Carver, 1989; Coffee \& Rees, 2008, 2009), and third, we examine the mechanisms (e.g., self-efficacy) through which attributions affect subsequent behaviour such as performance (Bandura, 1997; Gist \& Mitchell, 1992). In the present article we explore the 
WHEN THE CHIPS ARE DOWN 6

interactive effects of controllability and stability attributions for failure upon self-efficacy and performance following (a) a single induced failure (replication of Coffee et al., 2009, with the addition of exploring mediating effects), and (b) a repeated failure after initial feedback that causes of failure were uncontrollable and unlikely to change. In line with the results of Coffee et al., we predicted that, following a single failure on a given task, self-efficacy and future performance would not be adversely affected, so long as individuals believed either that the causes were under their control and/or were likely to change. In other words, we expected that following a single failure on a given task, self-efficacy and future performance would only deteriorate if individuals were led to believe that causes were beyond their control and unlikely to change (e.g., if individuals experienced perceptions of helplessness; cf. Abramson et al., 1978). Iin line with previous theorising (e.g., Bandura, 1986, 1997; Gist \& Mitchell, 1992), we hypothesised that the effects of attributions upon performance would be mediated by selfefficacy.

The second experiment was an exploratory study to examine the effects of new attributional feedback following initial perceptions that failure is beyond one's control and unlikely to change (e.g., following perceptions of helplessness). Whilst one would not expect successful athletes to exhibit a learned helplessness attributional style, it would be an error to assume that they never exhibit such an attributional pattern or enter a "learned helplessness spiral” (Hardy, Jones, \& Gould, 1996, p. 91). It is, therefore, important to investigate from an attributional perspective how individuals get out of this spiral. We hypothesised that effects of attributions upon performance would be mediated by self-efficacy. 


\section{WHEN THE CHIPS ARE DOWN 7}

\section{Experiment 1}

This experiment sought to replicate and extend the findings of Coffee et al. (2009), examining the impact of controllability and stability of causes of initial task failure on perceptions of self-efficacy and performance. We hypothesised that self-efficacy and performance would vary interactively as a function of these variables, and would be most harmed by failure where that failure was conceptualised as uncontrollable and unlikely to change in the future. We also hypothesised that self-efficacy would mediate the main and interactive effects of attributions upon performance.

\section{Method}

\section{Participants and Design}

Participants were a convenience sample of 80 athletes (47 male, 33 female; mean age 20.03, SD 1.03 years). All participants had a background of sports achievement at a high level. Twenty-four participants reported having no previous dart-throwing experience, 50 participants reported having very little experience, and six participants reported being somewhat experienced. The majority of participants were right-handed $(n=72)$. The experiment had a two-factor design, with two levels to each factor (controllability: high, low; stability: high, low). Participants were randomly assigned to conditions within the constraint of creating even groups (a balanced design: 20 participants in each condition).

\section{Materials}

The equipment consisted of a modified dartboard and three Harrows V-wing $25 \mathrm{~g}$ steeltip darts. The dartboard was $44.8 \mathrm{~cm}$ in diameter (standard size) and was divided into 10 evenly spaced concentric circles, with the innermost circle denoting a value of $10 \mathrm{pts}$, and the outermost circle denoting a value of $1 \mathrm{pt}$. The centre of the dartboard was $1.73 \mathrm{~m}$ from the ground. 


\section{WHEN THE CHIPS ARE DOWN 8}

\section{Procedure}

Ethical approval was granted for this experiment, and for Experiment 2, by the lead institution's ethics committee and participants provided informed consent prior to taking part. The procedure, including the content of the attributional manipulations, was informed by the protocol reported by Coffee et al. (2009). Participants entered a laboratory and were asked to complete a dart-throwing task, in which they would stand, blindfolded, $1.52 \mathrm{~m}$ (five feet) from the face of the dartboard, and then throw three darts. The scoring system (the sum of scores for three darts ranging from 0-30) was explained to participants and they were told that the objective of the task was to score as many points as they could. Participants were told when to commence throwing, and told that they would be informed of their total score after they had thrown the last dart.

Prior to this first task, participants completed a measure of self-efficacy (premanipulation self-efficacy). After their first performance, participants' actual score was recorded (pre-manipulation performance). All participants were provided with false negative feedback informing them that they had failed on the task (achieving a total score of just 6 with three darts). Failure was reinforced by inserting participants' initials next to a score of 6 on a false results sheet that indicated boundaries for different performance standards (where the labels 'failure,' 'average' and 'good' were adjacent to scores in the ranges 0-10, 11-20, and 21-30, respectively). The sheet also contained 41 false results ranging from 13 to 24 with a mean of $17.41(S D=$ 2.79). To check that participants perceived their first performance as a failure, they were asked "To what extent was this performance successful for you?" with responses ranging from 1 (not at all) to 7 (extremely) (responses ranged from 1 to 3 with a mean of $1.51, S D=.71$ ). 


\section{WHEN THE CHIPS ARE DOWN 9}

After this, participants were provided with oral instructions relevant to the condition to which they had been randomly assigned. These stated that "Having observed your performance, I can clearly see that the cause of your performance in this instance is something that you can [can't] control, and [but] something that is unlikely [likely] to change." Following the attributional manipulation, all participants completed measures of self-efficacy for their second performance (post-manipulation self-efficacy). The second performance followed the same procedure as the first performance. Following this, participants were provided with their actual score (post-manipulation performance). Finally, prior to debriefing, participants completed a post-experimental check in which they were asked to circle the condition, from a list of the four experimental conditions, to which they had been allocated. At this point all participants correctly identified the experimental condition to which they had been assigned.

\section{Measures}

Self-Efficacy. Self-efficacy was measured using a darts-specific questionnaire developed for this experiment. Development followed Bandura’s (e.g., 1997) recommendations and involved giving participants a list of 10 bands of scores they could potentially attain for dartthrowing performance. Each band of scores included three scores. For example, Band 1 included scores 1 to 3, Band 2 included scores 4 to 6, and Band 10 included scores 28-30. For each band of scores, participants were required to indicate whether they considered that they could attain a score in the band (yes/no response), and for every affirmative response, they were asked to give percentage estimate of their certainty of attaining a score in the band. Scores for self-efficacy were calculated by summing the total certainty scores and dividing by the total number of levels (10). 
WHEN THE CHIPS ARE DOWN 10

\section{Results and Discussion}

\section{Preliminary Analyses}

Analysis of variance (ANOVA) revealed that there were no significant differences in premanipulation scores of self-efficacy and performance due to gender, both $F_{\mathrm{s}}(1,78)<.25, p \mathrm{~s}>$ .05 , previous dart throwing experience, both $F \mathrm{~s}(2,77)<1.00, p \mathrm{~s}>.05$, and dominant throwing hand, both $F \mathrm{~s}(1,78)<2.93, p \mathrm{~s}>.05$. Accordingly, these variables were dropped from subsequent analyses. Mean scores for self-efficacy and performance are provided in Table 1. Main Analyses

Self-Efficacy. ANOVA revealed that there were no significant differences between groups in their pre-manipulation self-efficacy, $F(3,76)=.34, p>.05$. Assumptions for Analysis of covariance (ANCOVA) were satisfied, including evidence for homogeneous regression slopes (i.e., the slope of the regression line was the same for each condition). The results of a two-way (controllable/uncontrollable, stable/unstable) ANCOVA revealed that, after controlling for the effect of pre-manipulation self-efficacy, $F(1,75)=40.42, p<.01, \eta^{2}=.05$, there were significant main effects for controllability, $F(1,75)=14.82, p<.01, \eta^{2}=.17$, and stability, $F(1,75)=$ $14.06, p<.01, \eta^{2}=.02$, on post-manipulation self-efficacy. However, both effects were conditioned by an interaction between controllability and stability, $F(1,75)=8.56, p<.01, \eta^{2}=$ .01. This interaction is presented in Figure 1a. Following a simple ANCOVA, multiple comparisons tests identified significant differences in self-efficacy between participants in the uncontrollable and stable condition (adjusted mean $=18.06, S E=2.15)$, and participants in the controllable and stable condition (adjusted mean $=32.67, S E=2.16$ ), the controllable and unstable condition (adjusted mean $=34.44, S E=2.16$ ), and the uncontrollable and unstable condition (adjusted mean $=32.47, S E=2.15)$. Dependent $t$-tests indicated that self-efficacy 
scores of participants in the uncontrollable and stable condition decreased significantly across the two trials, $t(19)=4.11, p<.01, d=.94$, but that the scores of participants in the other three conditions did not change, $p \mathrm{~s}>.05$.

Performance. ANOVA revealed that there were no significant differences between groups in their pre-manipulation performance, $F(3,76)=1.53, p>.05$. Assumptions for ANCOVA were satisfied, including evidence for homogeneous regression slopes. The results of a two-way (controllable/uncontrollable, stable/unstable) ANCOVA revealed that, after controlling for the effect of pre-manipulation performance, $F(1,75)=61.06, p<.01, \eta^{2}=.07$, there were significant main effects for controllability, $F(1,75)=5.10, p<.05, \eta^{2}=.01$, and stability, $F(1,75)=4.50, p<.05, \eta^{2}=.01$, on post-manipulation performance. As shown in Figure $1 \mathrm{~b}$, these effects were qualified by a significant interaction between controllability and stability, $F(1,75)=5.49, p<.05, \eta^{2}=.01$. Following a simple ANCOVA, multiple comparisons tests identified significant differences in performance between participants in the uncontrollable and stable condition (adjusted mean $=6.81, S E=.71$ ), and participants in the controllable and stable condition (adjusted mean $=10.10, S E=.72$ ), the controllable and unstable condition (adjusted mean $=9.97, S E=.71)$, and the uncontrollable and unstable condition (adjusted mean $=10.02, S E=.72)$. Dependent $t$-tests indicated that the performance of participants in the uncontrollable and stable condition decreased significantly across the two trials, $t(19)=2.54, p<$ $.05, d=.53$, but that the scores of participants in the other three conditions did not change, $p \mathrm{~s}>$ .05 .

Tests for Mediation. Observed variable path analysis using LISREL 8.30 (Jöreskog \& Sörbom, 1996) was used to determine if self-efficacy mediated the effects of attributions upon performance. The mediation analyses were similar in design to the two-way ANCOVA, 
examining two main effects (controllability, stability) and one interactive effect (controllability * stability) of attributions upon outcomes. Controllability and stability were coded using contrast codes where controllable and stable were assigned the value +.5 , and uncontrollable and unstable assigned the value -.5 . The interaction (controllability * stability) was a function of the product of these codes (see, Cohen, Cohen, West, \& Aiken, 2003). Figure 2 demonstrates that selfefficacy fully mediated the main (Sobel's, 1982, test; controllability: $z=2.19, p<.05, r=.24$; stability: $z=-2.17, p<.05, r=-.24)$ and interactive, $z=1.97, p<.05, r=.22$, effects of attributions upon performance.

The results of this experiment demonstrated that, following failure, individuals experienced lower perceived self-efficacy and poorer performance relative to other conditions after being provided with uncontrollable and stable attributional feedback. Furthermore, across the two trials, self-efficacy and performance only declined for those participants who were led to believe that causes of failure were both beyond their control and unlikely to change. These results provide further support for the findings of Coffee et al. (2009) and extend them, demonstrating that self-efficacy fully mediated both the main and the interactive effects of attributions upon performance.

\section{Experiment 2}

Having demonstrated the negative effect of uncontrollable and stable attributions following an initial failure, the purpose of the second experiment was to examine the impact of controllability and stability attributions on self-efficacy and performance following an initial induced belief that failure is both beyond control and unlikely to change (e.g., following perceptions of helplessness). The experiment was exploratory in nature, although consistent with 
the first experiment we hypothesised that effects of attributions upon performance would be mediated by self-efficacy.

\section{Method}

\section{Participants and Design}

Participants were a convenience sample of 80 athletes (45 male, 35 female; mean age 21.96, SD 2.10 years). All participants had a background of sports achievement at a high level. Thirty-two participants reported having no previous dart-throwing experience and 48 participants reported having very little experience. The majority of participants were right-handed $(n=67)$. The experiment had the same two-factor design as experiment 1, involving random assignment of participants to one of four independent conditions within the constraint of creating even groups (a balanced design: 20 participants in each condition).

\section{Materials and Measures}

The materials and the measure of self-efficacy used in experiment 1 were used in experiment 2 .

\section{Procedure}

The second experiment followed the same procedure as Experiment 1 with the addition of an initial phase involving a manipulation of failure to uncontrollable and stable causes; thus, the second experiment consisted of a two-phase attributional manipulation. In phase 1, all participants were provided with false negative feedback (achieving a total score of just 6 with three darts) following their first trial and were informed that the cause of their failure was beyond their control and was unlikely to change (uncontrollable and stable). In phase 2, following their second trial, participants were again provided with false negative feedback, but this time, they were randomly assigned to one of four independent conditions (controllability: high, low; 
stability: high, low). Following the second manipulation, participants performed a third trial at the task. Participants completed measures of self-efficacy prior to all three trials and the actual scores of participants on all trials were recorded. Finally, prior to debriefing, participants completed a post-experimental check in which they were asked to circle the condition, from a list of the four experimental conditions, to which they had been allocated in phase 2 of the experiment. At this point all participants correctly identified the experimental condition to which they had been assigned.

\section{Results and Discussion}

\section{Preliminary Analyses}

ANOVA revealed that there were no significant differences in Trial 1 scores of selfefficacy and performance due to gender, both $F_{\mathrm{s}}(1,78)<3.57, p \mathrm{~s}>.05$, previous dart throwing experience, both $F_{\mathrm{s}}(1,78)<.33, p \mathrm{~s}>.05$, and dominant throwing hand, both $F_{\mathrm{s}}(1,78)<1.71, p \mathrm{~s}$ $>$.05. Accordingly, these variables were dropped from subsequent analyses. Dependent $t$-tests indicated that the initial manipulation of failure to uncontrollable and stable causes following Trial 1 was successful, resulting in scores of self-efficacy, $t(79)=5.43, p<.01, d=.42$, and performance, $t(79)=6.77, p<.01, d=.62$, that were significantly lower at Trial 2 . Mean scores for self-efficacy and performance across Trials 2 and 3 are provided in Table 2.

\section{Main Analyses}

Self-Efficacy. ANOVA revealed that there were no significant differences between groups in their Trial 2 scores of self-efficacy, $F(3,76)=.17, p>.05$. Assumptions for ANCOVA were satisfied, including evidence for homogeneous regression slopes. The results of a two-way (controllable/uncontrollable, stable/unstable) ANCOVA revealed that, after controlling for the effect of Trial 2 self-efficacy, $F(1,75)=126.57, p<.01, \eta^{2}=.14$, there were significant main 
effects for controllability, $F(1,75)=9.11, p<.01, \eta^{2}=.01$, and stability, $F(1,75)=6.51, p<$ $.05, \eta^{2}=.01$, on Trial 3 self-efficacy. However, both effects were conditioned by an interaction between controllability and stability, $F(1,75)=9.17, p<.01, \eta^{2}=.01$, presented in Figure 3 a. Following a simple ANCOVA, multiple comparisons tests identified significant differences in self-efficacy between participants in the controllable and unstable condition (adjusted mean $=$ $55.85, S E=3.27$ ), and participants in the controllable and stable condition (adjusted mean $=$ $37.61, S E=3.27)$, the uncontrollable and stable condition (adjusted mean $=37.62, S E=3.27$ ), and the uncontrollable and unstable condition (adjusted mean $=36.07, S E=3.27$ ). Dependent $t$ tests indicated that the self-efficacy of participants in the controllable and unstable condition increased significantly across trials 2 and $3, t(19)=-4.38, p<.01, d=-.92$, but that the scores of participants in the other three conditions did not change, $p \mathrm{~s}>.10$.

Performance. A one-way ANOVA revealed that there were no significant differences between groups in their Trial 2 scores of performance, $F(3,76)=.86, p>.05$. Assumptions for ANCOVA were satisfied, including evidence for homogeneous regression slopes. The results of a two-way (controllable/uncontrollable, stable/unstable) ANCOVA revealed that, after controlling for the effect of Trial 2 performance, $F(1,75)=264.42, p<.01, \eta^{2}=.21$, there were significant main effects for controllability, $F(1,75)=11.87, p<.01, \eta^{2}=.01$, and stability, $F(1$, $75)=11.51, p<.01, \eta^{2}=.01$, on Trial 3 performance. As shown in Figure $3 b$, these effects were qualified by a significant interaction between controllability and stability, $F(1,75)=4.53, p<$ $.05, \eta^{2}=.004$. Following a simple ANCOVA, multiple comparisons tests identified significant differences in performance between participants in the controllable and unstable condition (adjusted mean $=11.31, S E=.60)$, and participants in the controllable and stable condition (adjusted mean $=7.98, S E=.60)$, the uncontrollable and stable condition $($ adjusted mean $=7.19$, 
$S E=.60$ ), and the uncontrollable and unstable condition (adjusted mean $=7.97, S E=.60$ ).

Dependent $t$-tests indicated that the performance of participants in the controllable and unstable condition increased significantly across trials 2 and $3, t(19)=-6.26, p<.01, d=-.53$, but that the scores of participants in the other three conditions did not change, $p \mathrm{~s}>.10$.

Tests for Mediation. As in Experiment 1, self-efficacy mediated the main (controllability: $z=2.68, p<.01, r=.30 ;$ stability: $z=-2.34, p<.05, r=-.26)$ and interactive, $z=-2.69, p<.01$, $r=-.30$, effects of attributions upon performance. However, as Figure 4 demonstrates, the paths to performance from controllability and stability remained significant, suggesting only partial mediation of the main effects.

The preliminary analyses demonstrated that, following failure, individuals experienced lower perceived self-efficacy and performance on a second trial after being provided with uncontrollable and stable attributional feedback. Significantly, though, following orientation of an initial failure to uncontrollable and stable causes and then experiencing a repeated failure, self-efficacy and performance on a third trial only improved for those participants who were led to believe new information that causes of failure were both inside their control and likely to change. Consistent with the results of the first experiment, we found that all effects on performance were mediated by self-efficacy.

\section{General Discussion}

The experiments reported in this article demonstrate that, following an initial failure, induced attributions to uncontrollable and stable causes interact to produce significantly lower levels of self-efficacy and performance relative to conditions where individuals are led to form attributions that are controllable and/or unstable. Moreover, the results demonstrate that, across successive trials, individuals experience decrements in their self-efficacy and performance when 
they are led to attribute an initial failure to uncontrollable and stable causes. In Experiment 2, we further demonstrated that following initial negative feedback (uncontrollable and stable causes for failure) and then repeated failure, only a new induced belief that failure is within one's control and likely to change results in significantly higher levels of self-efficacy and performance relative to conditions where attributions are orientated to causes that are uncontrollable and/or stable. Moreover, self-efficacy and performance only increase when individuals are led to reattribute failure to controllable and unstable causes. Finally, both experiments demonstrate that self-efficacy is a mechanism through which attributions affect performance.

Across experiments, the manipulation of controllability and stability significantly affected self-efficacy and performance. The main effects of controllability demonstrate that in addition to stability (e.g., Bond et al., 2001), attributions to controllability affect subsequent selfefficacy (a large effect was observed in experiment 1) and performance. All main effects, however, were qualified by significant interactions. In Experiment 1, we replicated and extended the findings of Coffee et al. (2009), demonstrating that only induced attributions of initial failure to uncontrollable and stable causes result in significantly lower levels of self-efficacy and performance on a subsequent trial, and that self-efficacy mediates the effects of attributions upon performance. Replication is an important aspect of theory development, demonstrating if observed results are robust or merely fragile effects. Rozin (2009) stated that "we undervalue replication" (p. 438), especially following results that challenge traditional convention. The results of Coffee et al. challenged current models of applied practice that encourage individuals to form attributions that are controllable and unstable causes following initial failure (e.g., Orbach et al., 1997; Rudisill, 1989). The results of the first experiment suggest that the findings 
of Coffee et al. are robust: In accord with predictions from social identity theory (Tajfel \& Turner, 1979), the corroborated results suggest that following initial failure individuals pursue strategies of personal self-enhancement (Sedikides et al., 2003; Sedikides, Herbst, Hardin, \& Dardis, 2002) so long as they have some basis for believing that those strategies are likely to prove successful. In other words, following initial failure, levels of self-efficacy and performance were maintained, so long as individuals were led to believe that causes of failure were under their control and/or were likely to change. Conversely, a large negative effect on self-efficacy and a medium negative effect on performance were observed for those individuals who were led to believe that causes of failure were out of their control and unlikely to change.

In Experiment 2, we extended the literature by demonstrating that following an initial induced belief that failure is beyond one's control and unlikely to change (e.g., perceptions of helplessness; cf. Abramson et al., 1978), only a new induced belief that a repeated failure is within one's control and likely to change resulted in improved self-efficacy and performance in a subsequent trial. It would appear that once all possibilities to self-enhance are explicitly precluded (i.e., an initial failure is perceived as uncontrollable and stable), individuals only reinvest efforts and pursue strategies of personal self-enhancement when possibilities to selfenhance become clearly admissible — the failure is now in your control and is likely to change. In response to calls to identify strategies athletes might use to get out of "learned helplessness spirals" (Hardy et al., 1996, p. 91), the second experiment suggests that it is not sufficient for athletes to perceive that causes of repeated failure are controllable or unstable; rather, to positively affect subsequent self-efficacy and performance, it appears necessary for individuals to perceive that causes of repeated failure are both within their control and likely to change. A large positive effect on self-efficacy and a medium positive effect on performance were observed 
for those individuals who were led to believe new information that causes of failure were in their control and likely to change.

It is also important to note that all effects of attributions upon performance were mediated by self-efficacy with medium effect sizes observed for all results. Although self-efficacy has been proposed as a mechanism through which attributions may exert effects (e.g., Bandura, 1997; Gist \& Mitchell, 1992), empirical evidence to support such proposals is sparse and refers primarily to mediation of main effects and additive effects (e.g., Haney \& Long, 1995; Litt, 1988; Shields et al., 2006). Few, if any, researchers have examined if self-efficacy mediates interactive (mediated-moderation: see, Muller, Judd, \& Yzerbyt, 2005; Preacher, Rucker, \& Hayes, 2007) effects of attributions upon subsequent performance. To this end, the results of the present experiments contribute significantly to the literature, providing evidence that selfefficacy partially or fully mediates main effects (mediation) and fully mediates interactive effects (mediated-moderation) of attributions upon performance. In short, these results provide evidence that self-efficacy is a mechanism through which attributions affect subsequent behaviour such as performance.

The experiments reported in this article have some clear strengths. A considerable strength is the highly controlled experimental design, providing high internal validity for the results by reducing effects from confounding variables. Furthermore, the manipulations avoided the fundamental attribution researcher error (see, Russell, 1982) by detailing information based upon dimensional properties of attributions (controllability, stability). There are also some limitations that could be addressed in future research. For example, within the present experimental designs, there is a degree of uncertainty regarding the extent to which the attributional manipulations influenced participants' explanations for performance. Whilet 
participants were asked to identify to which group they had been assigned, recognising their own experimental condition among a list of possible conditions does not confirm that participants believed the attributional manipulations. In future, researchers might ask participants to complete the controllability and stability subscales of a measure of attributions (e.g., the CSGU; Coffee \& Rees, 2008) in relation to the induced failure following the manipulation. This procedure would provide an indication of whether the manipulation had achieved the desired effect. A related concern may be the absence of a control group. In future experiments, researchers might consider exploring a 3 (controllability: no information, low, high) x 3 (stability: no information, low, high) experimental design. This design would provide an opportunity to further examine the necessity of both controllability and stability in regard to effects upon outcomes. Finally, whilst the present results are theoretically interesting, future research is encouraged to explore the validity of the results in naturalistic settings.

The results have some important applied implications. Following an initial failure at a task, it appears that self-efficacy and performance are only negatively affected when people perceive no opportunities for personal self-enhancement. In situations of repeated failure, however, where individuals attribute initial failure to maladaptive attributions (uncontrollable and stable attributions), it would appear that individuals only reinvest efforts when possibilities to self-enhance become clearly admissible - the failure is now controllable and is likely to change. Maladaptive attributions following initial failure at a task, therefore, affect how individuals respond to attributional feedback following subsequent failure in similar situations. In other words, when athletes enter a learned helplessness spiral (uncontrollable and stable attributions for failure) it no longer becomes adaptive following failure to perceive some basis for personal self-enhancement (uncontrollable and unstable, or controllable and stable 
attributions); rather, it would appear necessary for athletes to wholeheartedly believe that they can self-enhance (controllable and unstable attributions for failure). Research is encouraged to examine behaviour in situations where little or no opportunities for personal advancement exist; for example, when selection for a team or squad is a result of favouritism rather than based on more conventional assessments of abilities, effort and suitability. Based upon the work of Haslam and Reicher (2006), it might be that individuals rechannel their energies in different directions through, for example, avoidance of or resistance to the task. Given the importance of coaches and, more generally, leaders, in future researchers might examine the importance of the social context. People do not engage in attributional thought in a vacuum; invariably, attributions are made in a social context (Hardy \& Jones, 1994). As such, in future researchers incorporating attributional retraining procedures would be well advised to consider social influences. 


\section{References}

Abramson, L. Y., Seligman, M. E. P., \& Teasdale, J. D. (1978). Learned helplessness in humans: Critique and reformulation. Journal of Abnormal Psychology, 87, 49-74.

Allen, M. S., Jones, M. V., \& Sheffield, D. (2009). Attribution, emotion, and collective efficacy in sports teams. Group Dynamics: Theory, Research, and Practice, 13, 205-217.

Alloy, L. B., Peterson, C., Abramson, L. Y., \& Seligman, M. E. P. (1984). Attributional style and the generality of learned helplessness. Journal of Personality and Social Psychology, 46, 681-687.

Anderson, C. A. (1999). Attributional style, depression, and loneliness: A cross-cultural comparison of American and Chinese students. Personality and Social Psychology Bulletin, 25, 482-499.

Anderson, C. A., \& Riger, A. L. (1991). A controllability attributional model of problems in living: Dimensional and situational interactions in the prediction of depression and loneliness. Social Cognition, 9, 149-181.

Bandura, A. (1986). Social foundations of thought and action. Englewood Cliffs, NJ: Prentice Hall.

Bandura, A. (1997). Self-efficacy: The exercise of control. New York: Freeman.

Bond, K. A., Biddle, S. J. H., \& Ntoumanis, N. (2001). Self-efficacy and causal attribution in female golfers. International Journal of Sport Psychology, 31, 243-256.

Carver, C. S. (1989). How should multifaceted personality constructs be tested? Issues illustrated by self-monitoring, attributional style, and hardiness. Journal of Personality and Social Psychology, 56, 577-585. 
Coffee, P., \& Rees, T. (2008). The CSGU: A measure of controllability, stability, globality, and universality attributions. Journal of Sport \& Exercise Psychology, 30, 611-641.

Coffee, P., \& Rees, T. (2009). The main and interactive effects of immediate and reflective attributions upon subsequent self-efficacy. European Journal of Sport Science, 9, 41-52.

Coffee, P., Rees, T., \& Haslam, S. A. (2009). Bouncing back from failure: The interactive impact of perceived controllability and stability on self-efficacy beliefs and future task performance. Journal of Sports Sciences, 27, 1117-1124.

Cohen, J., Cohen, P., West, S. G., \& Aiken, L. S. (2003). Applied multiple regression/correlation analysis for the behavioural sciences (3rd ed.). Mahwah, NJ: Lawrence Erlbaum Associates.

Collins, R. L. (1996). For better or worse: The impact of upward social comparison on selfevaluations. Psychological Bulletin, 119, 51-69.

Gernigon, C., \& Delloye, J. (2003). Self-efficacy, causal attribution, and track athletic performance following unexpected success or failure among elite sprinters. The Sport Psychologist, 17, 55-76.

Gist, M. E., \& Mitchell, T. R. (1992). Self-efficacy: A theoretical analysis of its determinants and malleability. Academy of Management Review, 17, 183-211.

Haney, C. J., \& Long, B. C. (1995). Coping effectiveness: A path analysis of self-efficacy, control, coping, and performance in sport competitions. Journal of Applied Social Psychology, 25, 1726-1746.

Hardy, L., \& Jones, G. (1994). Current issues and future directions for performance-related research in sport psychology. Journal of Sports Sciences, 12, 61-92. 
Hardy, L., Jones, J. G., \& Gould, D. (1996). Understanding psychological preparation for sport: Theory and practice of elite performers. Chichester, UK: Wiley.

Haslam, S. A., \& Reicher, S. D. (2006). Stressing the group: Social identity and the unfolding dynamics of responses to stress. Journal of Applied Psychology, 91, 1037-1052.

Jöreskog, K. G., \& Sörbom, D. (1996). LISREL 8: User's reference guide. Chicago, IL: SSI.

Kurman, J. (2006). Self-enhancement, self-regulation and self-improvement following failures. British Journal of Social Psychology, 45, 339-356.

Le Foll, D., Rascle, O., \& Higgins, N. C. (2006). Persistence in a putting task during perceived failure: Influence of state-attributions and attributional style. Applied Psychology: An international review, 55, 586-605.

Le Foll, D., Rascle, O., \& Higgins, N. C. (2008). Attributional feedback-induced changes in functional and dysfunctional attributions, expectations of success, hopefulness, and shortterm persistence in a novel sport. Psychology of Sport and Exercise, 9, 77-101.

Litt, M. D. (1988). Self-efficacy and perceived control: Cognitive mediators of pain tolerance. Journal of Personality and Social Psychology, 54, 149-160.

Muller, D., Judd, C. M., \& Yzerbyt, V. Y. (2005). When moderation is mediated and mediation is moderated. Journal of Personality and Social Psychology, 89, 852-863.

Orbach, I., Singer, R., \& Murphey, M. (1997). Changing attributions with an attribution training technique related to basketball dribbling. The Sport Psychologist, 11, 294-304.

Orbach, I., Singer, R., \& Price, S. (1999). An attribution training program and achievement in sport. The Sport Psychologist, 13, 69-82. 
Preacher, K. J., Rucker, D. D., \& Hayes, A. F. (2007). Addressing moderated mediation hypotheses: Theory, methods, and prescriptions. Multivariate Behavioral Research, 42, 185-227.

Rascle, O., Le Foll, D., \& Higgins, N. C. (2008). Attributional retraining alters novice golfers' free practice behaviour. Journal of Applied Sport Psychology, 20, 157-164.

Rozin, P. (2009). What kind of empirical research should we publish, fund, and reward? Perspectives on Psychological Science, 4, 435-439.

Rudisill, M. E. (1988). The influence of causal dimensions orientations and perceived competence on adults' expectations, persistence, performance, and the selection of causal dimensions. International Journal of Sport Psychology, 19, 184-198.

Rudisill, M. E. (1989). Influence of perceived competence and causal dimension orientation on expectations, persistence, and performance during perceived failure. Research Quarterly for Exercise and Sport, 60, 166-175.

Russell, D. (1982). The Causal Dimension Scale: A measure of how individuals perceive causes. Journal of Personality and Social Psychology, 42, 1137-1145.

Sedikides, C., Gaertner, L., \& Toguchi, Y. (2003). Pancultural self-enhancement. Journal of Personality and Social Psychology, 84, 60-79.

Sedikides, C., Herbst, K. C., Hardin, D. P., \& Dardis, G. J. (2002). Accountability as a deterrent to self-enhancement: The search for mechanisms. Journal of Personality and Social Psychology, 83, 592-605.

Seligman, M. E. P., Nolen-Hoeksema, S., Thornton, N., \& Thornton, K. M. (1990). Explanatory style as a mechanism of disappointing athletic performance. Psychological Science, 1, 143-146. 
Shields, C. A., Brawley, L. R., \& Lindover, T. I. (2006). Self-efficacy as a mediator of the relationship between causal attributions and exercise behaviour. Journal of Applied Social Psychology, 36, 2785-2802.

Sobel, M. E. (1982). Asymptotic confidence intervals for indirect effects in structural equation models. In S. Leinhardt (Ed.), Sociological methodology (pp. 290-312). Washington DC: ASA Press.

Tajfel, H., \& Turner, J. C. (1979). An integrative theory of intergroup conflict. In W. G. Austin \& S. Worchel (Eds.), The social psychology of intergroup relations (pp. 33-47). Monterey, CA: Brooks/Cole.

Weiner, B. (1985). An attributional theory of achievement motivation and emotion. Psychological Review, 92, 548-573.

Weiner, B. (1986). An attributional theory of achievement motivation and emotion. New York: Springer. 
Table 1

Mean Pre-Manipulation and Mean and Adjusted Mean Post-Manipulation Scores for SelfEfficacy and Performance in Experiment 1.

\begin{tabular}{|c|c|c|c|c|c|c|c|}
\hline \multirow{3}{*}{$\begin{array}{l}\text { Dependent } \\
\text { Variable }\end{array}$} & \multirow[b]{3}{*}{ Condition } & & & \multicolumn{4}{|c|}{ Post-Manipulation } \\
\hline & & \multicolumn{2}{|c|}{ Pre-Manipulation } & \multicolumn{2}{|c|}{ Obtained } & \multicolumn{2}{|c|}{ Adjusted } \\
\hline & & Mean & $S E$ & Mean & $S E$ & Mean & $S E$ \\
\hline \multirow[t]{4}{*}{ Self-Efficacy } & $\mathrm{CS}$ & 27.45 & 2.48 & 31.42 & 1.95 & 32.67 & 2.16 \\
\hline & $\mathrm{CU}$ & 31.70 & 3.04 & 35.33 & 3.13 & 34.44 & 2.16 \\
\hline & US & 30.72 & 3.49 & 18.45 & 2.25 & 18.06 & 2.15 \\
\hline & UU & 29.88 & 3.34 & 32.44 & 3.09 & 32.47 & 2.15 \\
\hline \multirow[t]{4}{*}{ Performance } & $\mathrm{CS}$ & 10.35 & .95 & 11.05 & .89 & 10.10 & .72 \\
\hline & $\mathrm{CU}$ & 8.95 & .87 & 9.85 & .97 & 9.97 & .71 \\
\hline & US & 9.30 & .85 & 6.95 & 1.10 & 6.81 & .71 \\
\hline & UU & 7.85 & .63 & 9.05 & .83 & 10.02 & .72 \\
\hline
\end{tabular}

Note. $N=80$ ( $n=20 /$ condition). $\mathrm{CS}=$ controllable and stable condition. $\mathrm{CU}=$ controllable and unstable condition. $\mathrm{US}=$ uncontrollable and stable condition. $\mathrm{UU}=$ uncontrollable and unstable condition. 
WHEN THE CHIPS ARE DOWN 28

Table 2

Mean Trial 2 and Mean and Adjusted Mean Trial 3 Scores for Self-Efficacy and Performance in Experiment 2.

\begin{tabular}{|c|c|c|c|c|c|c|c|}
\hline \multirow{3}{*}{$\begin{array}{l}\text { Dependent } \\
\text { Variable }\end{array}$} & \multirow[b]{3}{*}{ Condition } & & & \multicolumn{4}{|c|}{ Trial 3} \\
\hline & & \multicolumn{2}{|c|}{ Trial 2} & \multicolumn{2}{|c|}{ Obtained } & \multicolumn{2}{|c|}{ Adjusted } \\
\hline & & Mean & $S E$ & Mean & $S E$ & Mean & $S E$ \\
\hline \multirow[t]{4}{*}{ Self-Efficacy } & $\mathrm{CS}$ & 37.93 & 4.40 & 38.23 & 5.09 & 37.61 & 3.27 \\
\hline & $\mathrm{CU}$ & 39.20 & 4.01 & 57.73 & 4.92 & 55.85 & 3.27 \\
\hline & US & 35.05 & 3.61 & 35.40 & 6.17 & 37.62 & 3.27 \\
\hline & UU & 37.03 & 4.95 & 35.80 & 5.01 & 36.07 & 3.27 \\
\hline \multirow[t]{4}{*}{ Performance } & $\mathrm{CS}$ & 7.70 & 1.09 & 7.65 & 1.36 & 7.98 & .60 \\
\hline & $\mathrm{CU}$ & 9.30 & 1.32 & 12.50 & 1.39 & 11.31 & .60 \\
\hline & US & 6.75 & 1.02 & 5.95 & 1.16 & 7.19 & .60 \\
\hline & UU & 8.45 & 1.23 & 8.35 & 1.12 & 7.97 & .60 \\
\hline
\end{tabular}

Note. $N=80$ ( $n=20 /$ condition). $\mathrm{CS}=$ controllable and stable condition. $\mathrm{CU}=$ controllable and unstable condition. US = uncontrollable and stable condition. UU = uncontrollable and unstable condition. 


\section{Figure Captions}

Figure 1. The effects of controllability and stability on (a) perceived self-efficacy and (b) task performance (with pre-manipulation scores entered as covariates; adjusted mean scores plotted) for experiment 1. Error bars indicate standard errors.

Figure 2. Mediation of the effects of attributions upon performance by self-efficacy for experiment 1 .

Figure 3. The effects of controllability and stability on (a) perceived self-efficacy and (b) task performance (with trial 2 scores entered as covariates; adjusted mean scores plotted) for experiment 2. Error bars indicate standard errors.

Figure 4. Mediation of the effects of attributions upon performance by self-efficacy for experiment 2 .

For Figures 2 and 4:

Note. $*$ denotes unstandardised path coefficient $p<.05 . * *$ denotes unstandardised path coefficient $p<.01$. 
Figure 1

a

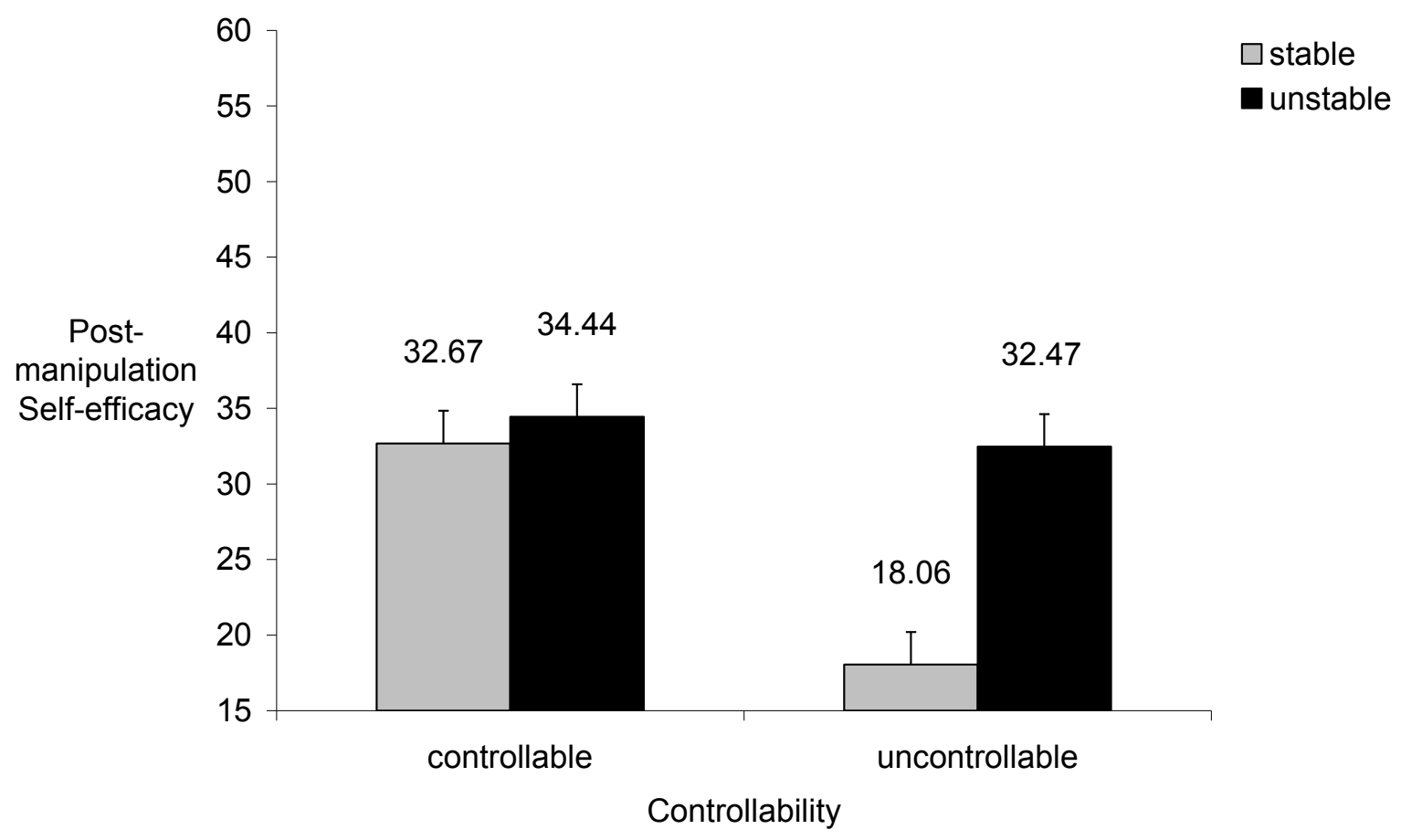

b

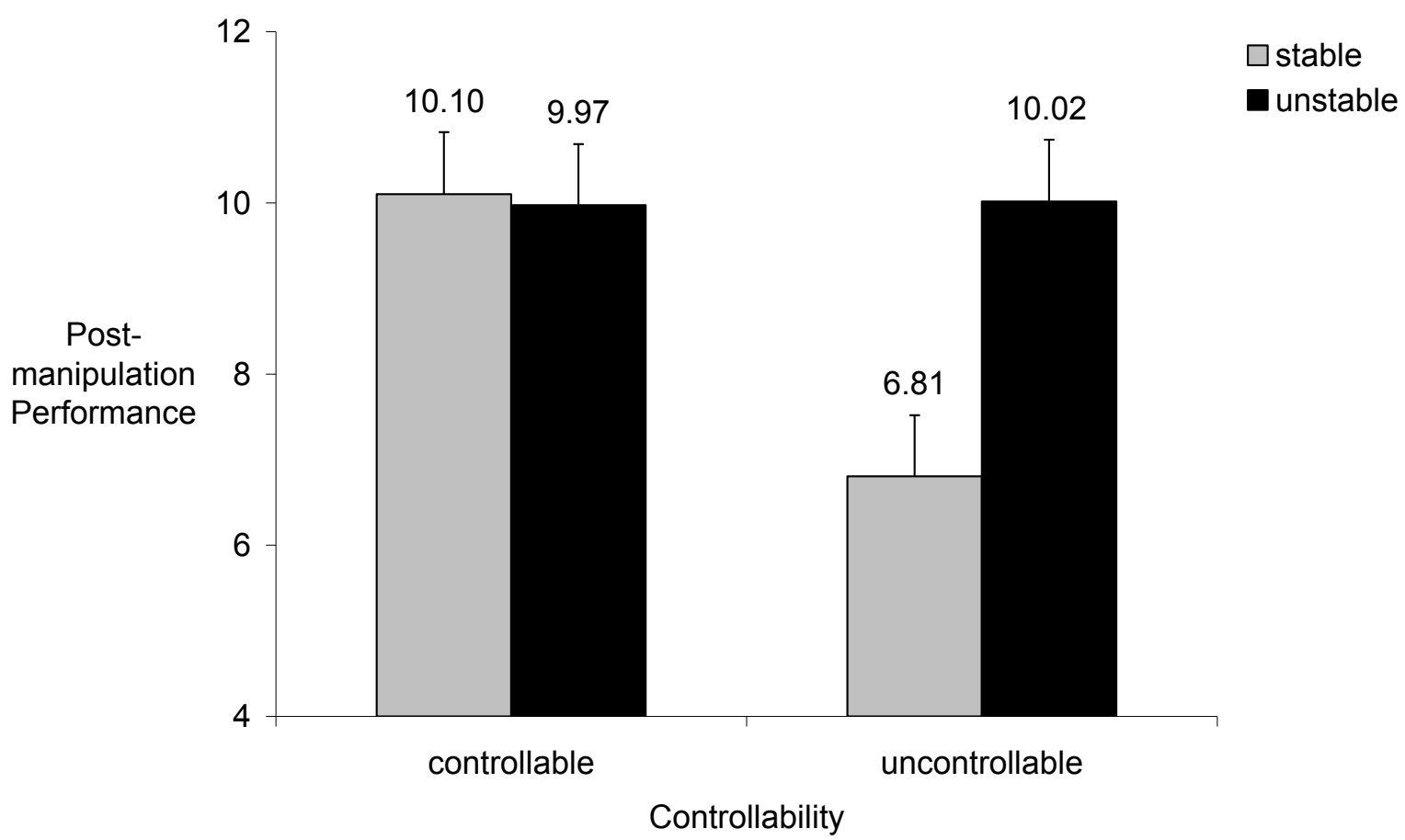


Figure 2

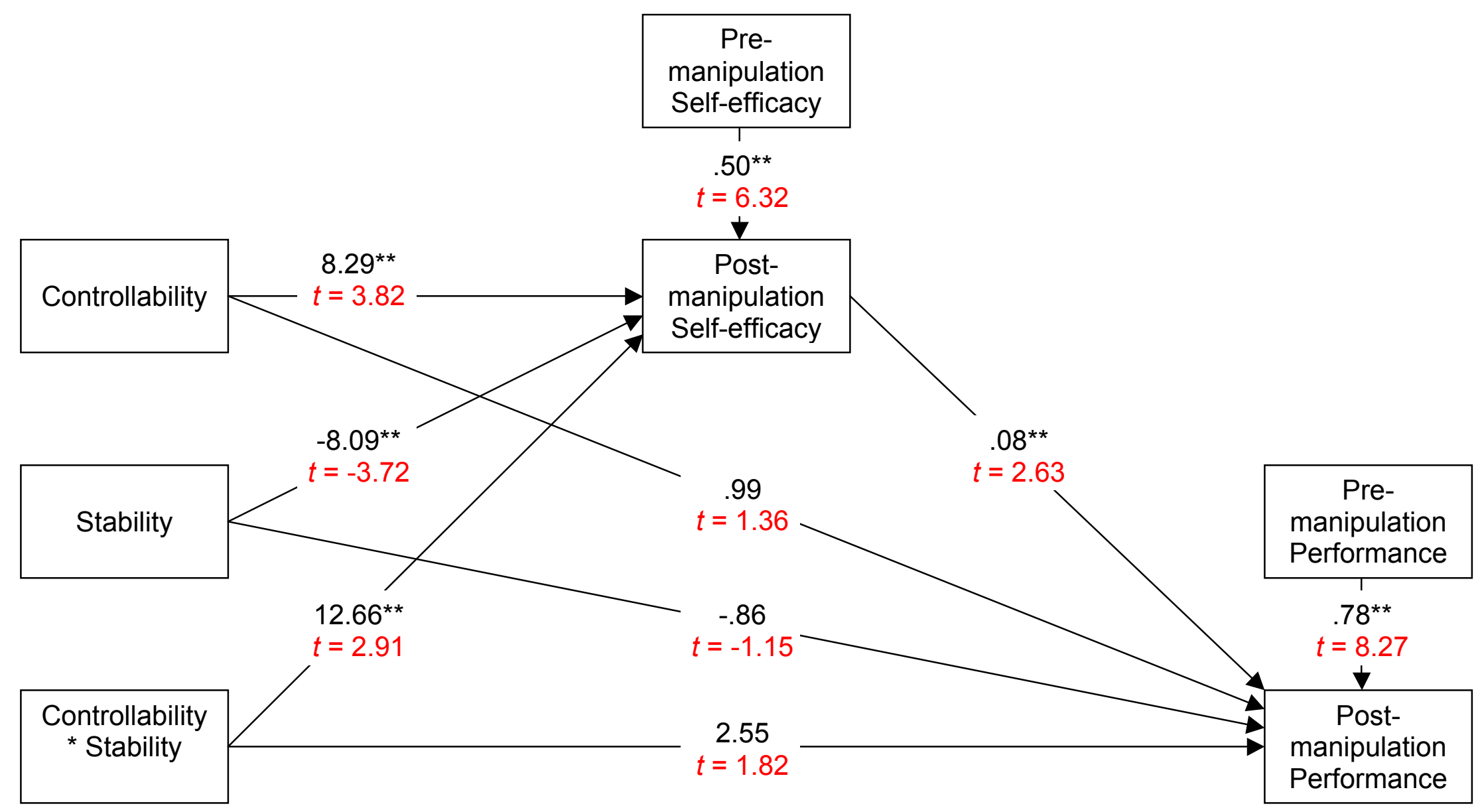


Figure 3

a

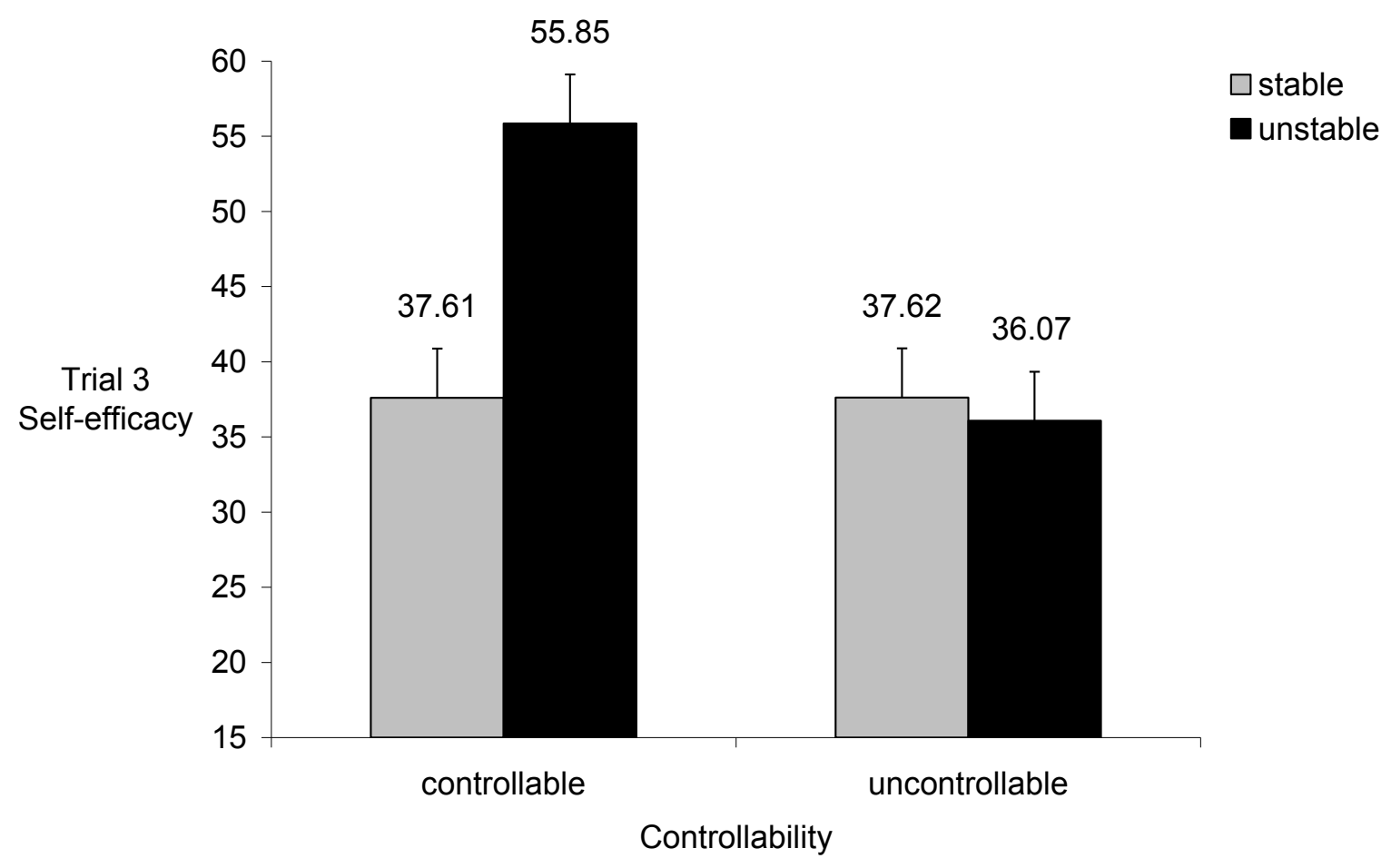

b

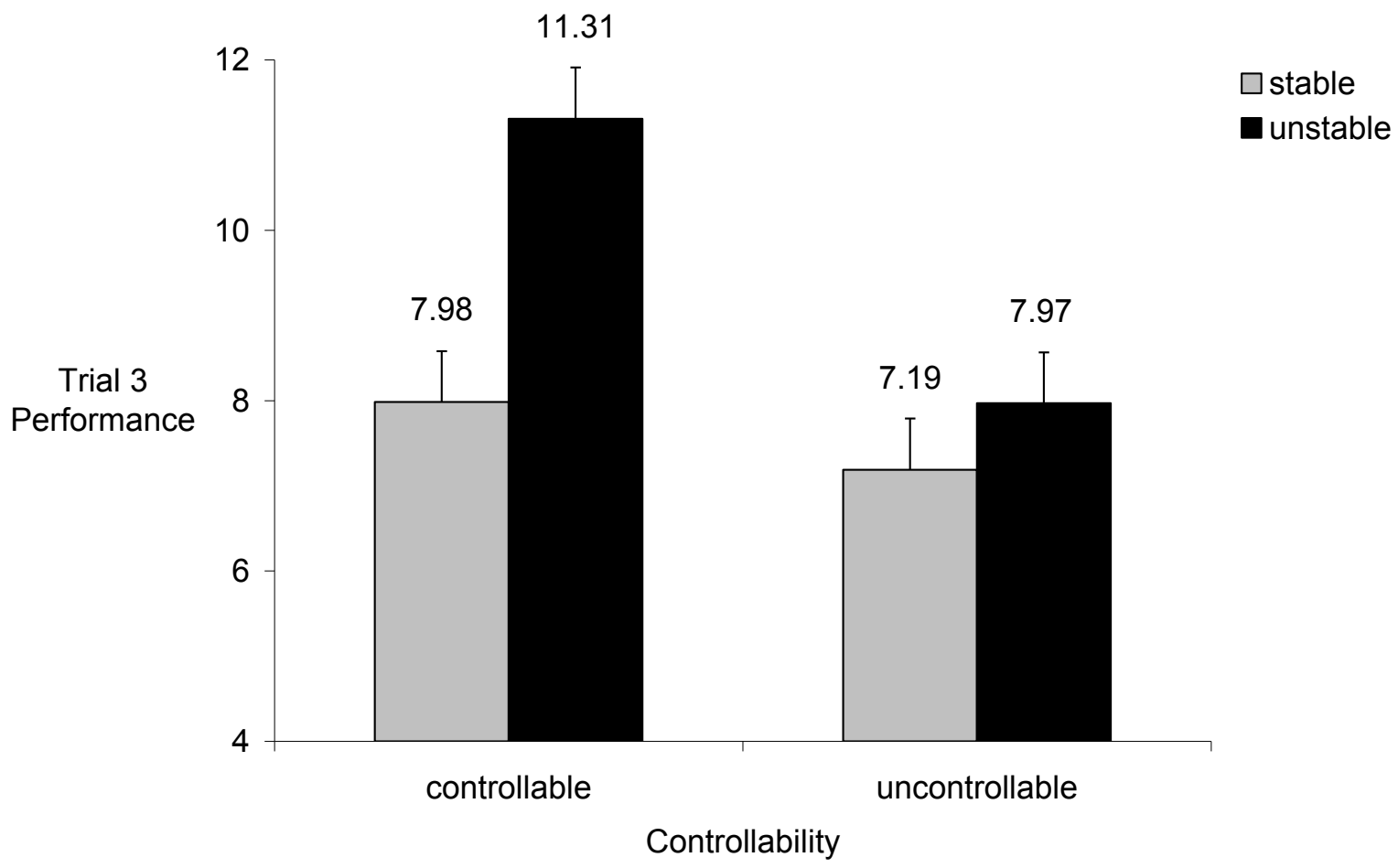


Figure 4

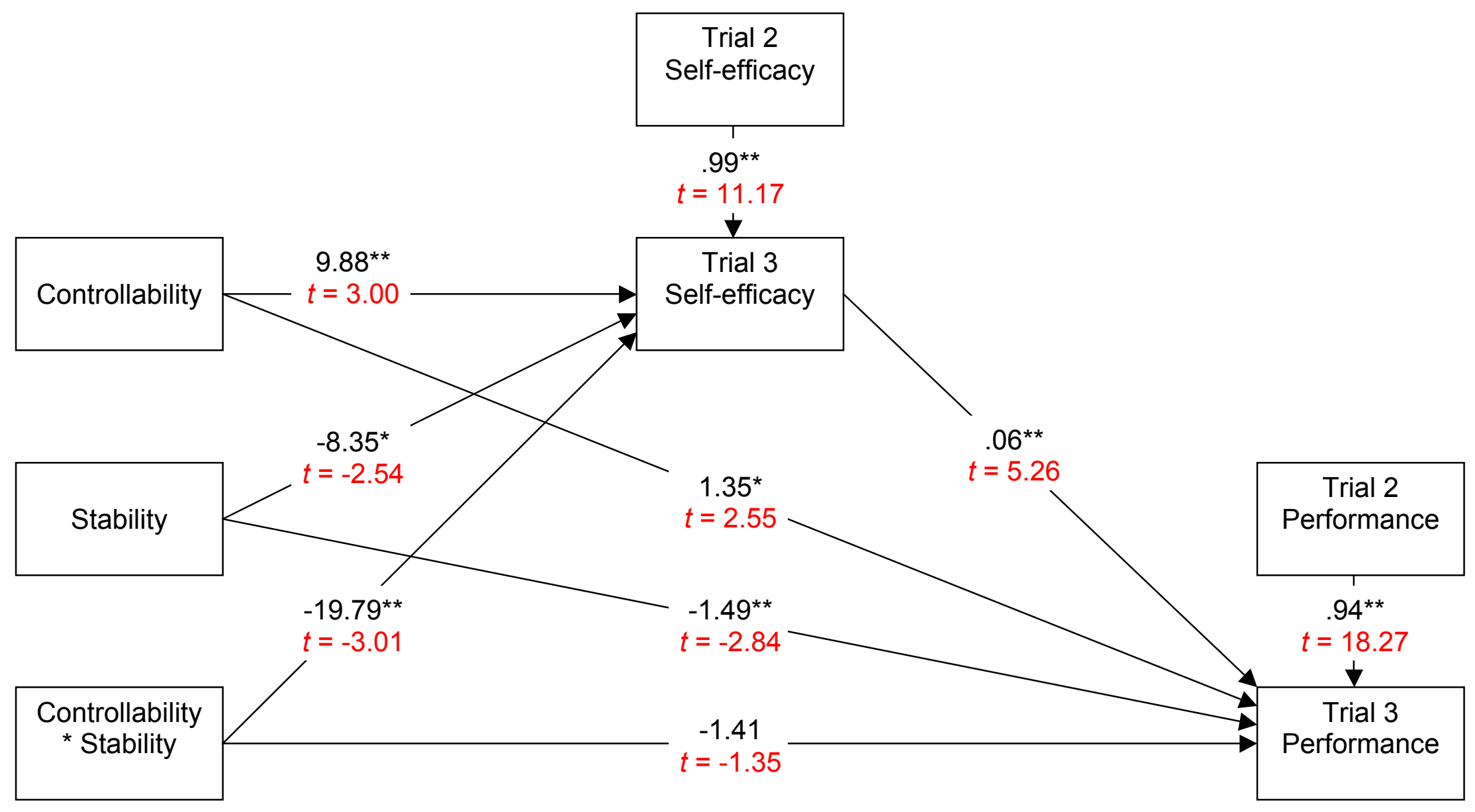

